\title{
Investigation of acoustic transmission beneath a railway vehicle by using statistical energy analysis and an equivalent source model
}

\author{
Hui $\mathrm{Li}^{1}$, David Thompson ${ }^{1}$, Giacomo Squicciarini ${ }^{1}$, Xiaowan Liu ${ }^{1}$, Martin Rissmann ${ }^{2}$, Francisco D. Denia ${ }^{3}$, \\ Juan Giner-Navarro ${ }^{3}$ \\ ${ }^{1}$ Institute of Sound and Vibration Research, University of Southampton, \\ Southampton SO17 1BJ, United Kingdom \\ ${ }^{2}$ Vibratec, Chemin du Petit Bois BP 36, F-69131 Ecully Cedex, France \\ ${ }^{3}$ Centro de Investigación en Ingeniería Mecánica, Universitat Politècnica de València, \\ Camino de Vera s/n, 46022 Valencia, Spain
}

\begin{abstract}
An approach is presented for modelling the noise propagation beneath the train floor and this is applied to rolling noise sources. It is assumed that the sound incident on the train floor is made up of a direct and a reverberant component. A combination of two numerical modelling approaches is considered to deal with these: an equivalent source model, to represent the direct component, and statistical energy analysis (SEA) for the reverberant part. In the equivalent source model, the wheel is replaced by monopole and dipole sources, which represent its radial and axial radiation. The rail vertical vibration and the sleepers are replaced by arrays of monopole sources while the rail lateral vibration is replaced by an array of lateral dipoles. The sound power of the rolling noise is obtained by using the TWINS model. In the SEA model, the region beneath the train floor is divided into several volumes and the power input to these subsystems is assumed to be due to the first reflections from the train floor and the ground. The reverberant and direct sound have very similar contributions to the total sound power incident on the train floor although this depends on how the equipment is arranged beneath the train. The modelling approach is verified by comparing the predicted sound pressure levels with laboratory measurements and with field tests.
\end{abstract}

Key words: SEA, equivalent source model, train noise, under-floor noise.

\section{Introduction}

The noise inside railway vehicles is an important aspect of passenger comfort. Noise from various sources is transmitted into the vehicle by both airborne and structure-borne paths $[1,2]$. For the airborne paths, the sound field beneath the vehicle is important in determining the sound incident on the floor. One of the most important noise sources in this region is the rolling noise 
radiated by the wheels and track. Some of this noise is absorbed by the ballast, some propagates away from the vehicle through gaps at the sides, and the rest is incident on the floor. The sound reaching the floor is mostly reflected back beneath the train. The equipment under the train adds additional reflections and scattering and a reverberant sound field can develop beneath the vehicle [3]. This can also be enhanced by the presence of fairings along the sides, which cause further reflections into the region beneath the train. Understanding and improving the acoustic environment beneath the vehicle can help in controlling the airborne component of interior noise that is transmitted through the train floor as well as the exterior noise.

To achieve this goal, this paper builds upon existing knowledge of rolling noise modelling and proposes a method to predict the sound field under the train floor. The approach is based on the TWINS model [4], in which, the wheel/rail system is excited by the combined roughness of the wheel and rail through a contact spring [2]. The rail vibration is represented using a Timoshenko beam whereas the wheel vibration is calculated using a modal summation based on a finite element model. The sound radiation of the wheel and rail is calculated from their vibration using engineering models [2]. Zhang et al. [5] have recently extended the sound radiation models used for the railway track to take account of the proximity of the ground.

In an alternative approach, Nilsson et al. [6] developed a coupled waveguide finite element and boundary element approach (also called a $2.5 \mathrm{D}$ approach) to predict the noise radiated by the rail. The vibration of the rail and the sound radiated were determined using a $2 \mathrm{D}$ domain as a function of wavenumber in the third dimension. Ryue et al. [7] used the $2.5 \mathrm{D}$ model to investigate the sound radiation efficiency and directivity of the rail in the presence of a reflective ground. Kitagawa and Thompson [8] modelled the rail vibration as a Timoshenko beam and used an equivalent source model, based on [9], to study the sound propagation from it, but the vehicle was not considered in any of the studies mentioned here.

Research on the acoustic environment beneath a vehicle is limited. Some researchers have studied the airborne noise transmission of rolling noise to the vehicle interior, but they did not specifically study the acoustic environment below the vehicle. For instance, Dai et al. [10] and Zheng et al. [11] proposed a statistical energy flow method to predict the full spectrum sound inside a railway vehicle but the acoustic behaviour beneath the train floor was not explained and the sound power incident on the train floor was calculated by using commercial software. Zheng 
et al. [12] also used an energy finite element analysis method to study the noise inside a railway vehicle considering rolling noise as one of its main sources. However, again, in their approach, the noise below the vehicle was not fully explained. Moreover, the complex interaction between source and equipment beneath the vehicle, including absorption and reflection, was not considered in their work. Numerical modelling methods to study the acoustical behaviour beneath a railway vehicle with acoustic shields mounted on the train and the track were developed by Jones et al. [3] using a combination of Statistical Energy Analysis (SEA) and the Boundary Element Method (BEM). As the focus of their work was mainly on the performance of the shields in reducing exterior noise, the distribution of sound incident on the train floor was not studied.

In the context of railway noise, SEA has been used by Forssén et al. [13] to model the interior sound field of a 1:5 scale railway vehicle by subdividing it into five coupled subsystems. As the usual SEA solution only gives the average energy of each system, in their work the spatial decay within a subsystem is adjusted using formulas from literature on sound decay in corridors. They analysed the sound in the vehicle in the one-third octave bands between 125 and $4000 \mathrm{~Hz}$ (at full scale). The predicted sound pressure levels in the train cabin along its axis were in reasonable agreement with the measured results at most frequencies.

There are some problems in using SEA to model acoustic environments that are extended in one or more dimension, such as a train cabin or the region below the floor. Fahy [14] noted that the SEA assumption of 'weak coupling' would not be valid for two coupled cavity subsystems without any impedance mismatch at the open boundary between them. However, he suggested that if the sound field within an automotive vehicle compartment approximates to a diffuse field in the 'mid-frequency' range, it could nevertheless be acceptable to divide the enclosed air volume into arbitrarily small subsystems.

Jang and Hopkins [15] compared an SEA model and a ray tracing model for the prediction of sound transmission in long spaces with a point source at one end. They showed that predictive SEA that includes only direct coupling between subsystems tends to over-predict the decrease in sound pressure level compared with the results of ray tracing at low frequency while underpredicting it at high frequency. However, if SEA is used with modified coupling loss factors that include indirect coupling it can give good agreement with ray tracing. 
Despite this limitation, it has been suggested that the SEA method can be used to study the noise in regions of space characterised by a diffuse field $[14,16]$. Following Jones et al. [3], SEA is adopted in this paper as a possible modelling approach and the final results are compared with experiments. Jones et al. [3] divided the sound field beneath the train into a direct and a reverberant part. The same approach is used in this paper. The direct sound due to the wheel, the rail and the sleepers will be determined using equivalent sources [8].

The paper is organised as follows. The modelling of the direct sound is explained in Section 2 and the reverberant sound in Section 3. Section 4 investigates the relative contributions of the direct and reverberant parts to the overall sound. Experimental validation is given in Section 5 by comparing predicted results with laboratory measurements and in Section 6 using field measurements on a static and a running train.

\section{Direct sound}

\subsection{Noise sources}

Rolling noise is generated by vibration of the wheels, the rails and the sleepers. The TWINS model [4] has become an established method for predicting the noise from these various sources. To illustrate the proposed method, predictions are presented in this section for a wheel with a straight web and radius $0.435 \mathrm{~m}$ running on a typical ballasted track fitted with UIC 60 rails. The rail pads have a vertical dynamic stiffness of $100 \mathrm{MN} / \mathrm{m}$, and lateral dynamic stiffness of $13 \mathrm{MN} / \mathrm{m}$, corresponding to a relatively soft support. A typical measured rail roughness spectrum is used in the TWINS model to predict the sound power. The main parameters of the wheelset are listed below in Table 1 and those for the track in Table 2.

Table 1. Parameters used to represent the wheel.

\begin{tabular}{lr}
\hline Wheel radius & $0.435 \mathrm{~m}$ \\
Width of tyre & $0.135 \mathrm{~m}$ \\
Width of web & $0.032 \mathrm{~m}$ \\
Tyre inner radius & $0.36 \mathrm{~m}$ \\
Hub radius & $0.135 \mathrm{~m}$ \\
Wheelset gauge & $1.5 \mathrm{~m}$ \\
Wheelset mass & $1100 \mathrm{~kg}$ \\
\hline
\end{tabular}


Table 2. Parameters used to represent a railway track (UIC60).

\begin{tabular}{lcr}
\hline & Vertical & Lateral \\
\hline Rail bending stiffness $\left(\mathrm{N} \mathrm{m}^{2}\right)$ & $6.42 \times 10^{6}$ & $1.07 \times 10^{6}$ \\
Rail shear coefficient & 0.4 & 0.4 \\
Rail damping loss factor & 0.02 & 0.02 \\
Mass per length $(\mathrm{kg} / \mathrm{m})$ & 60 & \\
Cross receptance level $(\mathrm{dB})$ & -7 & $13 \times 10^{6}$ \\
Pad stiffness (N/m) & $100 \times 10^{6}$ & 0.2 \\
Pad damping loss factor & 0.2 & \\
Sleeper mass (half, kg) & 140 & $35 \times 10^{6}$ \\
Distance between sleepers $(\mathrm{m})$ & 0.6 & 2.0 \\
Ballast damping stiffness $(\mathrm{N} / \mathrm{m})$ & $200 \times 10^{6}$ & \\
Ballast loss factor & 1.0 & \\
\hline
\end{tabular}

Based on these parameters, the sound power predicted using the TWINS model is shown in Figure 1. These results are for a single wheel and the corresponding track vibration (one rail). Due to the soft rail pads, the rail is the largest source of sound power and dominates the spectrum from the $315 \mathrm{~Hz}$ band to the $2 \mathrm{kHz}$ band. Below this frequency range the sleeper is the most important source while the wheel becomes significant at high frequency [2, 4].

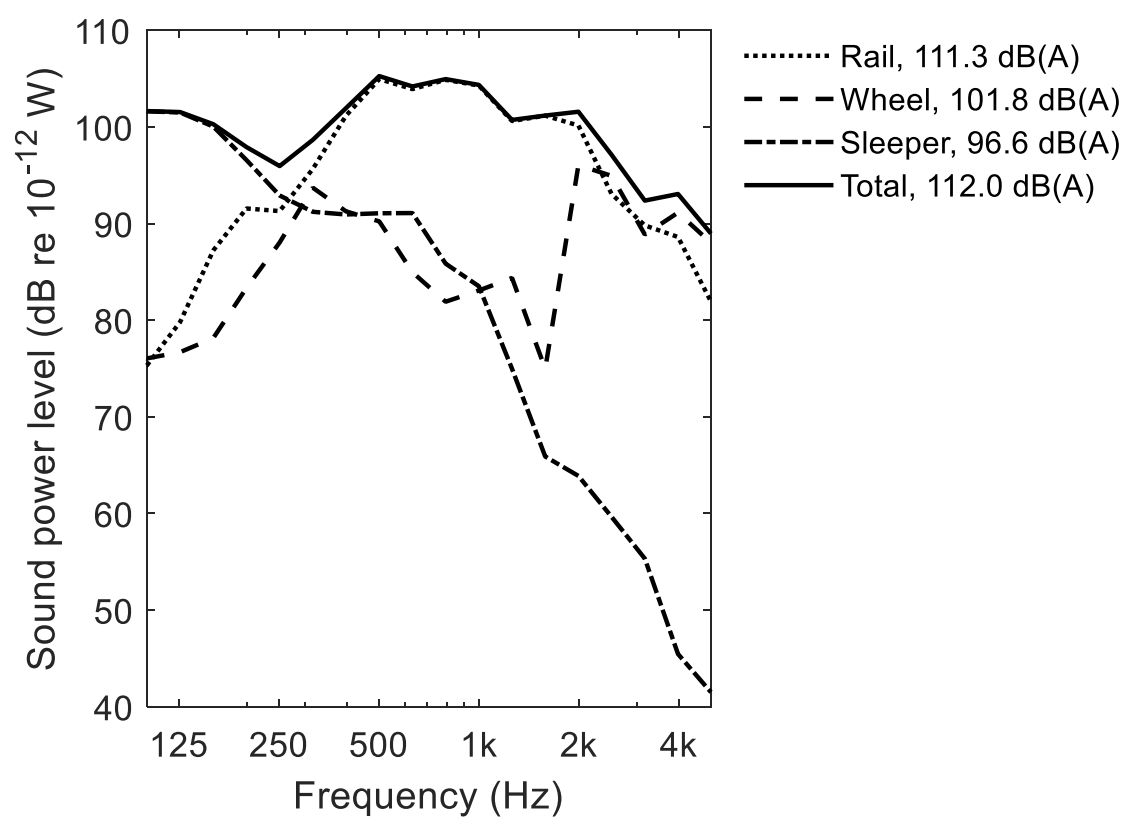

Figure 1. Sound power of rolling noise obtained from TWINS model. 
In the modelling approach outlined in next sections, the procedure is based on the sound power from a single wheel and the corresponding track vibration as shown in Figure 1. The total contribution from all the wheels in a vehicle can be obtained by combining the results for different wheels assuming they are incoherent sources.

\subsection{Wheel noise}

The sound power from the wheel can be divided into components associated with its radial and axial vibration. Generally, for the radial direction, the sound pressure field around the wheel can be adequately approximated by an omni-directional source, whereas, for the axial motion of the wheel, a dipole approximation is more reasonable [2]. Therefore, a monopole and a lateral dipole are used to model the directivity of the sound radiated by the radial and axial components of the wheel motion, respectively.

The methodology used to calculate the direct sound incident on the train floor due to the wheel is illustrated in Figure 2(a). A point source ( $S$ in Figure 2(a)) is located at the geometrical centre of the wheel, which is assumed to be $0.63 \mathrm{~m}$ above the sleepers and ballast (the height of the rail plus the wheel radius). For a harmonic monopole source, the amplitude of the sound pressure incident on the train floor, at a position defined by vector $\mathbf{r}_{m}$, is expressed as [17]

$$
p\left(\mathbf{r}_{m}\right)=\mathrm{i} \omega \rho_{0} Q \frac{\mathrm{e}^{-\mathrm{i} k R_{s m}}}{4 \pi R_{s m}}
$$

where $Q$ is the volume velocity of the monopole, $R_{s m}=\left|\mathbf{r}_{m}-\mathbf{r}_{s}\right|$ is the distance from the source location $(s)$ to the receiver location $(m)$ on the train floor, $k=\omega / c_{0}$ is the acoustic wavenumber, $\rho_{0}$ is the air density, $c_{0}$ is the speed of sound and $\omega$ is the angular frequency. In the numerical model the volume velocity is initially set to be unity and the mean square pressure is later adjusted by using the sound power calculated in TWINS as described below. By differentiating Equation (1), the particle velocity of the sound incident on the train floor is given by

$$
\mathbf{u}\left(\mathbf{r}_{m}\right)=\left(1+\mathrm{i} k R_{s m}\right) \frac{Q\left(\mathbf{r}_{m}-\mathbf{r}_{s}\right)}{4 \pi R_{s m}{ }^{3}} \mathrm{e}^{-\mathrm{i} k R_{s m}}
$$

For the sound incident on the ground surface due to this source, the sound pressure and particle 
velocity can be calculated in a similar manner. The sound power from the source (representing the wheel) incident on the ground will be discussed later in relation to the reverberant sound. The sound pressure and particle velocity due to a dipole are calculated in a similar way but including the dipole directivity factor [17].

\subsection{Rail noise}

The rail noise radiation is also treated separately for the vertical and lateral vibration directions [2]. For vibration in the vertical direction, the rail is replaced by a line array of $N$ correlated monopoles located with equal spacing $D$ along its axis. Based on [8], the source separation $D$ is set to be smaller than a quarter of the acoustic wavelength at the frequency of interest, as well as less than a quarter of the structural wavelength. A different source spacing is chosen for each frequency according to this criterion. For the lateral direction a similar approach is used but the rail is represented by an array of lateral dipoles.

The volume velocity amplitude of source $n$ is denoted by $Q_{n}$ and its location by $\mathbf{r}_{n}$. A series of receivers located on the train floor are again considered, defined by vectors $\mathbf{r} m$. The distance between source $n$ and receiver location $m$ is denoted by $R_{m n}=\left|\mathbf{r}_{m}-\mathbf{r}_{n}\right|$. The methodology to calculate the direct sound at the train floor due to the rail is illustrated in Figure 2(b).

(a)

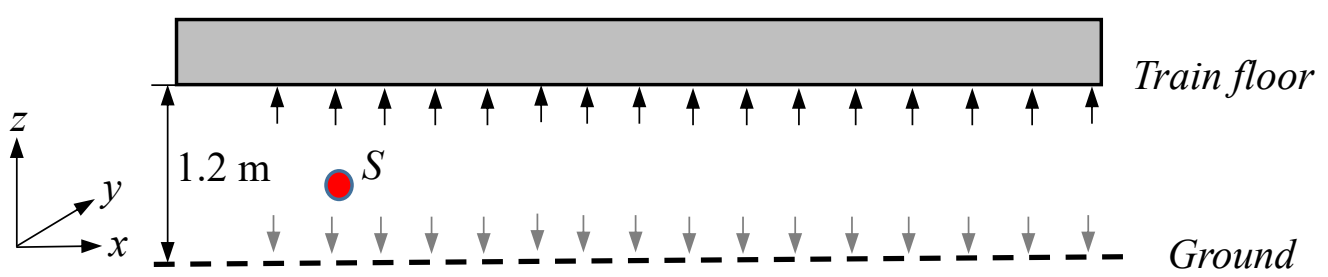

(b)

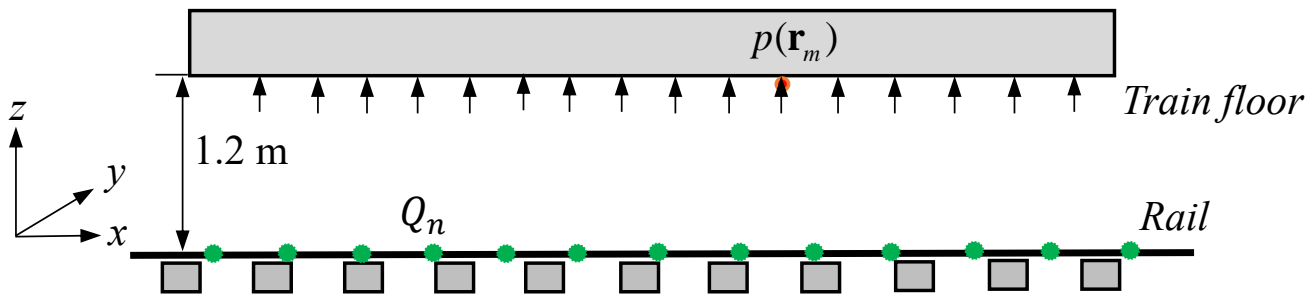

Figure 2. Schematic view of the methodology used to determine the direct component of sound incident on the floor. (a) Direct sound from wheel; (b) Equivalent noise source model for the rail. $\bullet$ point sources, $\rightarrow$ incident on the train floor, $\rightarrow$ sound from the wheel incident on the ground. 
For a given direction and angular frequency $\omega$, the sources representing the rail are assumed to be mutually coherent, so that their relative phase must be considered [8]. The sound pressure amplitude at receiver location $m$ due to rail vertical vibration is given by

$$
p\left(\mathbf{r}_{m}\right)=\sum_{n=1}^{N}\left(\mathrm{i} \rho_{0} c_{0} k \frac{Q_{n}}{4 \pi R_{m n}} \mathrm{e}^{-\mathrm{i} k R_{m n}}\right)
$$

When calculating the sound pressure at the floor location (the floor is omitted in calculating the incident sound), the ground reflection and absorption should be considered. This is not shown in the above Equation (3) but is incorporated in the source term that is obtained from the TWINS model [4]. When using the sound power of the rolling noise to adjust the equivalent source models, the ground reflection and absorption are thus included. Similarly, the particle velocity can be written as

$$
\mathbf{u}\left(\mathbf{r}_{m}\right)=\sum_{n=1}^{N}\left(1+\mathrm{i} k R_{m n}\right) \frac{Q_{n}\left(\mathbf{r}_{m}-\mathbf{r}_{n}\right)}{4 \pi R_{m n}{ }^{3}} \mathrm{e}^{-\mathrm{i} k R_{m n}}
$$

The complex volume velocity amplitudes $Q_{n}$ are chosen to correspond to the vibration velocity of the rail at each position due to a unit force at $x=0$, calculated according to the transfer mobility of the rail,

$$
Q_{n}=Q_{0} Y\left(x_{n}\right)
$$

where $x_{n}$ is the distance from the excitation point and $Q_{0}$ is a 'calibration factor' which depends on the separation between the sources, the size of the rail cross-section and frequency [18]. The transfer mobility $Y(x)$ of the rail is derived from a Timoshenko beam model based on a continuous two-layer support [2], expressed as

$$
Y(x)=u_{1} \mathrm{e}^{-\mathrm{i} k_{x}|x|}-\mathrm{i} u_{2} \mathrm{e}^{-\beta|x|}
$$

where $k_{x}$ is the wavenumber corresponding to the predominantly propagating wave and $\beta$ corresponds to the evanescent wave; $u_{1}$ and $u_{2}$ are the corresponding wave amplitudes. The imaginary part of $k_{x}$ corresponds to the decay with distance along the rail, which can be expressed as a track decay rate (TDR) in $\mathrm{dB} / \mathrm{m}[2]$ as $\Delta=-8.686 \operatorname{Im}\left(k_{x}\right)$. The vertical and 
lateral decay rates of the rail for the current parameters are plotted in Figure 3.

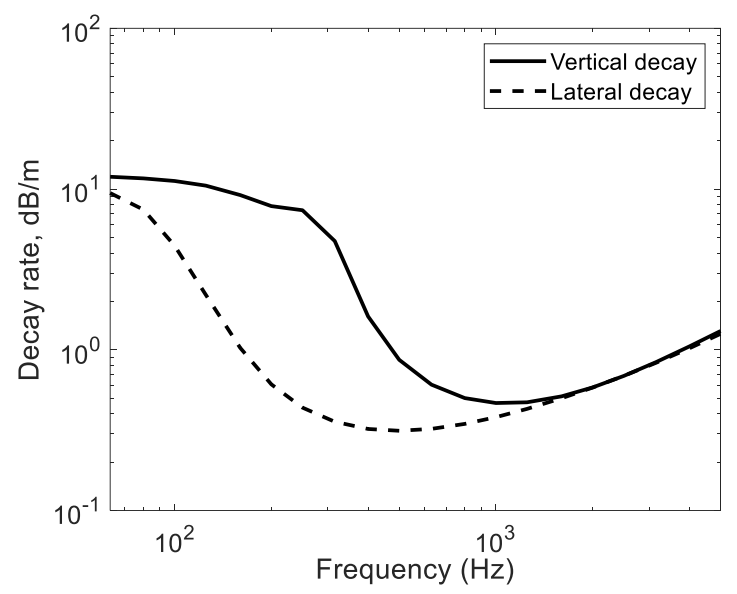

Figure 3. Decay rate of the rail for the parameters in Table 2.

\subsection{Sleeper noise}

Sleepers are typically about $2.5 \mathrm{~m}$ long and 0.2 to $0.25 \mathrm{~m}$ wide. When the vibration is transmitted from the rail to the sleepers, it causes the sleepers to vibrate mainly in the vertical direction. The distribution of the sleeper vibration in the $x$-direction (i.e. along the track) can be derived from the rail transfer mobility and the ratio of the sleeper displacement to that of the rail, given by [2]

$$
r=\frac{s_{p}}{s_{p}+s_{b}-\omega^{2} m_{s}}
$$

where $s_{p}$ is the rail pad stiffness in the vertical direction, $s_{b}$ is the ballast stiffness and $m_{s}$ is the sleeper mass. Damping is introduced by making the stiffnesses complex. From the rail transfer mobility and this ratio, the vibration velocity of the sleeper can be obtained. In this work, sleepers are treated as rigid bodies and are represented acoustically by sets of monopole sources radiating noise into a half-space. Five equally-spaced monopole sources are used to replace each half sleeper.

\subsection{Direct sound pressure on train floor due to rolling noise}

The direct sound pressure incident on the train floor is calculated due to each source, as described above. The sound power obtained from the TWINS model is used to adjust these results according to the ratio of the sound power obtained from the TWINS model to that from the point source models used to replace the wheel, the rail and the sleepers. In each case this 
ratio is expressed as

$$
q=\frac{W_{\mathrm{TWINS}}}{W_{\mathrm{eq}}}
$$

where $W_{\text {TWINS }}$ is the sound power of rolling noise obtained from the TWINS model and $W_{\text {eq }}$ is the sound power obtained from the equivalent source model. These factors are determined separately for each source (wheel axial and radial, rail vertical and lateral, and sleepers) and each frequency band and applied to the corresponding squared pressure. The sound power from the equivalent source models $W_{\text {eq }}$ is found by integrating the sound intensity over a suitable farfield surface. For the rail, the radiating length is limited to $60 \mathrm{~m}$ on either side of the excitation position and this part of the rail is enclosed in a virtual cylinder with radius $2.5 \mathrm{~m}$ and length 60 $\mathrm{m}$ on each side of the excitation. This length ensures that, even for the lowest decay rate, the contribution from the parts of the rail not included in the calculation is negligible. In fact, for the lowest decay rate, $0.3 \mathrm{~dB} / \mathrm{m}$ at $500 \mathrm{~Hz}$ in the lateral direction (see Figure 3), the vibration has decayed by $18 \mathrm{~dB}$ after $60 \mathrm{~m}$. The sound power of the equivalent sources representing the wheel is calculated by enclosing the point sources by a virtual sphere of radius $5 \mathrm{~m}$ and integrating the sound intensity.

\section{The reverberant sound}

\subsection{SEA model}

As indicated previously, the reverberant component of the sound is studied by using Statistical Energy Analysis (SEA) [18]. This is an efficient method for obtaining the average response of complicated systems. The space beneath the vehicle floor is subdivided into several segments as indicated in Figure 4. The length of a train coach is normally in the range 17 to $26 \mathrm{~m}$. In this section, a $26 \mathrm{~m}$ long train coach without fairings is used as an example. The centre of the bogie is assumed to be $3.2 \mathrm{~m}$ from its end. The width of the underfloor cavity is assumed to be $3.6 \mathrm{~m}$ and the height of the train floor above the ballast and sleepers is taken as $1.2 \mathrm{~m}$. The region beneath the train floor is divided into seven segments, as shown in Figure 4. The length of segments 1 and 7 is taken as $5 \mathrm{~m}$ to include the whole bogie region; the remaining five segments are $3.2 \mathrm{~m}$ long. The geometry information of each subsystem is listed in Table 3. 


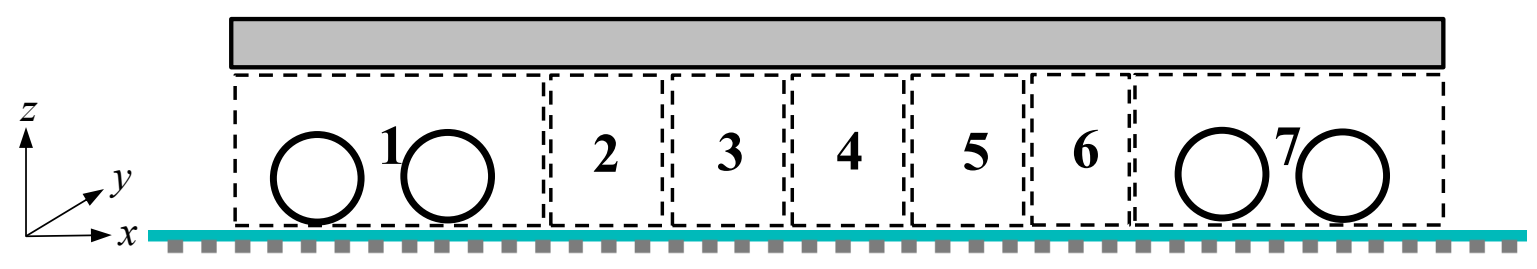

Figure 4. SEA model for investigating acoustic behaviour below the train.

Table 3. Geometry information of each subsystem for the SEA model beneath the train.

\begin{tabular}{|l|c|c|c|c|c|c|c|}
\hline Subsystem & 1 & 2 & 3 & 4 & 5 & 6 & 7 \\
\hline Length $(\mathrm{m})$ & 5 & 3.2 & 3.2 & 3.2 & 3.2 & 3.2 & 5 \\
\hline surface area $\left(\mathrm{m}^{2}\right)$ & 56.6 & 39.3 & 39.3 & 39.3 & 39.3 & 39.3 & 56.6 \\
\hline Volume $\left(\mathrm{m}^{3}\right)$ & 21.6 & 13.8 & 13.8 & 13.8 & 13.8 & 13.8 & 21.6 \\
\hline Interface area $\left(\mathrm{m}^{2}\right)$ & 4.3 & 4.3 & 4.3 & 4.3 & 4.3 & 4.3 \\
\hline
\end{tabular}

The use of the SEA method to solve an acoustic problem generally requires more than that at least five modes of each subsystem are present in each one-third octave band. The number of modes in a volume below frequency $f$ can be calculated by [20]

$$
N_{i}=\frac{4 \pi}{3} V_{i}\left(\frac{f}{c_{0}}\right)^{3}+\frac{\pi}{4} S_{i}\left(\frac{f}{c_{0}}\right)^{2}+\frac{L_{i}}{8}\left(\frac{f}{c_{0}}\right)^{1}
$$

where $V_{i}$ is the volume, $S_{i}$ is the total surface area and $L_{i}$ the total edge length of each subsystem. The number of modes in each frequency band is the difference between the value of $N_{i}$ at the upper and lower band limits of frequency band. This indicates that subsystems 1 and 7 have six modes in the $125 \mathrm{~Hz}$ band and subsystems 2-6 have eight modes in the $160 \mathrm{~Hz}$ band. Thus, the SEA model with this subdivision meets the requirement at and above the $160 \mathrm{~Hz}$ band. Assuming there is no coupling between two unconnected subsystems, the power balance for the SEA system is given by [18]

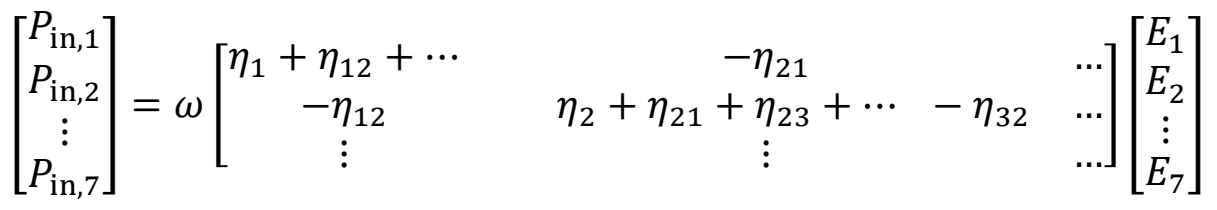

where $P_{\mathrm{in}, i}$ is the power input to subsystem $i, E_{i}$ is the energy in the respective subsystem, $\eta_{i j}$ are coupling loss factors between subsystems $i$ and $j(i \neq j)$ and $\eta_{i}$ is dissipation loss factor in 
subsystem $i$. If the input powers, coupling loss factors and dissipation loss factors are known, the energy in each subsystem can then be calculated. Expressions for the dissipation loss factor $\eta_{i}$ in each subsystem and the coupling loss factors $\eta_{i j}$ between two acoustic subsystems can be found in [18]

$$
\begin{gathered}
\eta_{i}=\frac{c_{0} S_{i} \bar{\alpha}_{i}}{4 \omega V_{i}} \\
\eta_{i j}=\frac{c_{0} S_{i j} \tau_{i j}}{4 \omega V_{i}}
\end{gathered}
$$

where $S_{i}$ is the total surface area of subsystem $i, \bar{\alpha}_{i}$ is its average absorption coefficient, $V_{i}$ is the volume for subsystem $i, S_{i j}=S_{j i}$ is the interface area between cavities $i$ and $j$, and $\tau_{i j}$ is transmission coefficient between them. As there is no partition between adjacent subsystems, it can be assumed that $\tau_{i j}$ can be set to 1 [13].

To calculate the dissipation loss factor, the absorption coefficient of the surfaces of each volume is required. As the sides are open and the exterior domain is not included in the model, the 'absorption coefficients' of the open areas are expected to be 1. If there are fairings on the train sides, an appropriate absorption coefficient should be used for these surfaces. Based on experience the absorption coefficient on the train floor is set to be 0.2 . For the absorption coefficient of the ballast, measured values from [19] are used, see Figure 5(a). These increase from about 0.1 at $100 \mathrm{~Hz}$ to 0.6 above $1 \mathrm{kHz}$. The sleepers are made of concrete in most cases, so their absorption coefficient is set to be 0 . The average absorption coefficient of the ground takes account of the respective areas of the ballast and the sleepers. The respective areas of the ballast and sleepers depend on the particular design of the track. It is common that the sleeper spacing is $0.6 \mathrm{~m}$ and the sleeper width is $0.2 \mathrm{~m}$, in which case the ballast covers $2 / 3$ of the ground area and the sleepers cover the remaining $1 / 3$. This is used as the assumption in this section.

To ensure that the assumption of a diffuse field is valid, the mean absorption coefficient in each subsystem should be small compared with unity [21]. In this SEA model, illustrated in Figure 4, the mean absorption coefficient in each subsystem can be calculated by 


$$
\bar{\alpha}=\sum_{n=1}^{4} \frac{s_{n} \alpha_{n}}{S}
$$

where $s_{n}$ is the effective area of each surface and $\alpha_{n}$ is the corresponding absorption coefficient. In each subsystem only four surfaces are considered: the section of the train floor and the ground and surfaces at the two sides of the train. $S$ is the total area of the four surfaces. The interface between two adjacent subsystems is considered as a transmission path and not a source of dissipation. All the subsystems in this SEA model have the same mean absorption coefficients and the results are plotted against frequency in Figure 5(b). The mean absorption coefficients are between 0.3 and 0.5 . Therefore the assumption of a diffuse field can be considered valid.
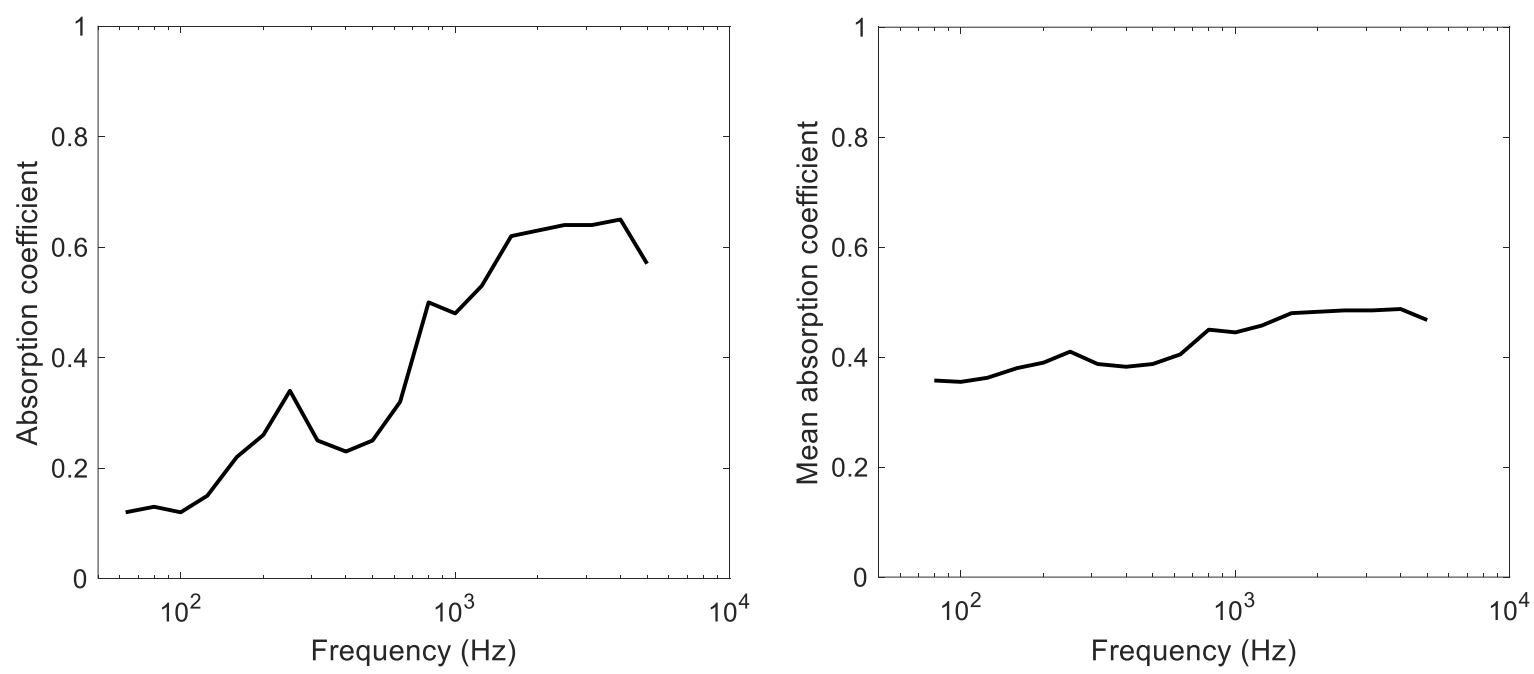

Figure 5. (a) Absorption of ballast, measured data from [19], (b) mean absorption coefficient in each subsystem.

Apart from the diffuse field assumption, the SEA method is based on 'weak coupling' between two connected subsystems, although there is no universal, commonly accepted definition of what the terms 'weak coupling' means as yet in an SEA sense. Fahy [14] pointed out that the vibration/acoustic fields in any one subsystem are weakly coupled if each subsystem exhibits 'local' mode behaviour such that, when it is directly excited, minimal coherent modal motion occurs in other subsystems. In other words, 'weak coupling' is associated with there being predominantly local modes in each subsystem. Fahy [14] also indicated that in a long space, like the enclosure of a train cabin, the air volume exhibits well-separated (discrete) acoustic 
resonance frequencies. The associated modes are undoubtedly global in character, exhibiting strong interference patterns and highly non-uniform distributions of energy density. As a result, 'weak coupling' may not be satisfied in the low frequency range but it is reasonable to imagine that it is valid at sufficiently high frequencies. An alternative statement of 'weak coupling' is that two subsystems can be described as being weakly connected if energy cannot flow freely across the interface between them [22]. Generally, this requires that dissipation is stronger than coupling. This can be reflected by the dissipation and coupling loss factors in each subsystem [23]. They are shown in Figure 6 for the subsystems in the middle region beneath the train which indicates that the dissipation loss factor is greater than the coupling loss factor, which to some extent verifies the 'weak coupling' assumption. The two subsystems at the ends have larger absorptive surfaces, so they will satisfy this criterion from a lower frequency. Considering the number of modes in each subsystem and the assumption of a diffuse field and 'weak coupling' between two adjacent subsystems, the SEA method is applicable in and above the $160 \mathrm{~Hz}$ band.

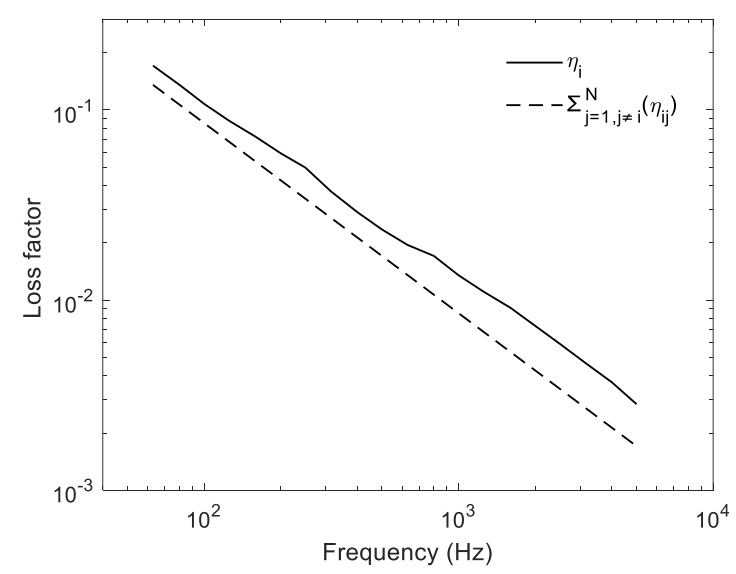

Figure 6. Loss factors of the subsystems in the middle region beneath the train, the index $i$ referring to the subsystems $2-6$.

\subsection{Input power and reverberant sound}

The power input to the SEA system is calculated from the direct sound after the first reflection, allowing for the absorption coefficient of the surface. This is done for reflections from the train floor, the fairings and the ground. The sound power incident on the train floor can be calculated by 


$$
W=\int_{y_{1}}^{y_{2}} \int_{a}^{b} I_{z} \mathrm{~d} y \mathrm{~d} x
$$

where $y$ is the coordinate in the width direction, extending from $y_{1}$ to $y_{2}$ relative to one rail, and $a, b$ are the limits of $x$ for each segment in the train length direction. $I_{z}$ is the normal component of the sound intensity incident on the train floor:

$$
I_{z}=\frac{1}{2} \operatorname{Re}\left(p u_{z}^{*}\right)
$$

where $p$ and $u_{\mathrm{z}}$ are the sound pressure and normal velocity amplitudes of the sound incident on the train floor. These are calculated for each source separately as described in Section 2. The sound power reflected by the ground consists only of the contribution from the wheels. This is because the direct sound radiated by the rails (and sleepers) is calculated allowing for the ground reflection. The sound power incident on the ground surface due to the wheel can be calculated in a manner similar to Equations (14) and (15). The power reflected from the ground (allowing for its absorption) is added as an input for each segment. The same is done for fairings if they are present. The total power input to the SEA model is expressed as

$$
P_{\text {in }}=W_{f}\left(1-\alpha_{f}\right)+W_{b}\left(1-\alpha_{b}\right)
$$

where $W_{f}$ is the sound power incident on the train floor, and the fairings if present, $W_{b}$ is the sound power from the wheel incident on the ground, $\alpha_{f}$ and $\alpha_{b}$ are the absorption coefficients of the train floor and the ground. Figure 7(a) shows the input power for each subsystem for several example one-third octave bands for the model in Figure 4. The relative levels of the different bands correspond to the inputs determined from the TWINS results and the sound power decays with distance at different rates in each band according to the TDR and the acoustic transmission between subsystems. By solving the SEA problem as given in Equation (10), the energy in each subsystem can then be calculated. This is shown in Figure 7(b) for the same example frequency bands. 

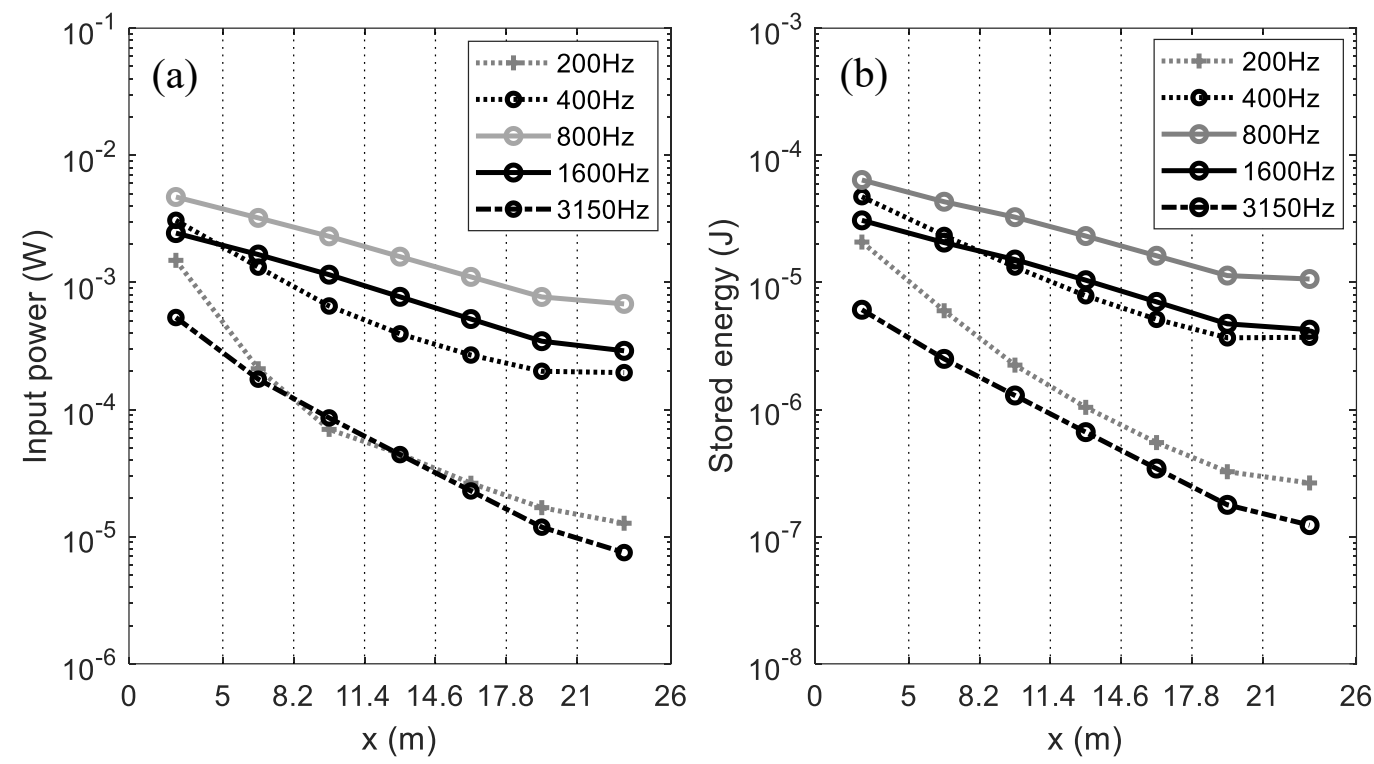

Figure 7. (a) Power input to each segment in the SEA system due to one wheel and associated track vibration, (b) stored energy in each subsystem of the SEA system ( $x=0$ is the end of the carriage).

The spatially-averaged mean-square sound pressure in each subsystem and frequency band is calculated from the energy $E_{i}$ and the volume $V_{i}$

$$
\overline{p_{r e v, i}^{2}}=\frac{\rho c_{0}^{2} E_{i}}{V_{i}}
$$

which forms the reverberant component of the sound.

\section{Contributions of direct and reverberant sound}

The direct sound incident on the train floor is determined by summing the mean-square sound pressures from the wheels, rails and sleepers. The total direct sound pressure incident on the train floor in three example frequency bands is shown in Figure 8, in which the wheel/rail contact location is at $(2.2 \mathrm{~m}, 0.0 \mathrm{~m})$. 
(a)

(dB)

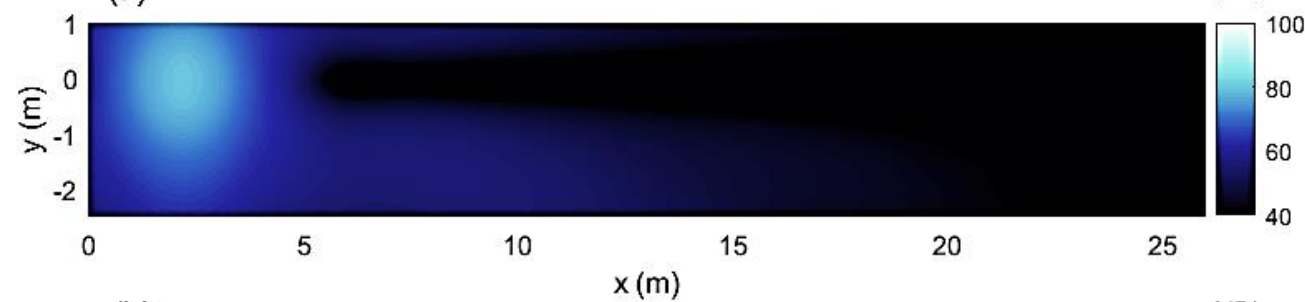

(b)

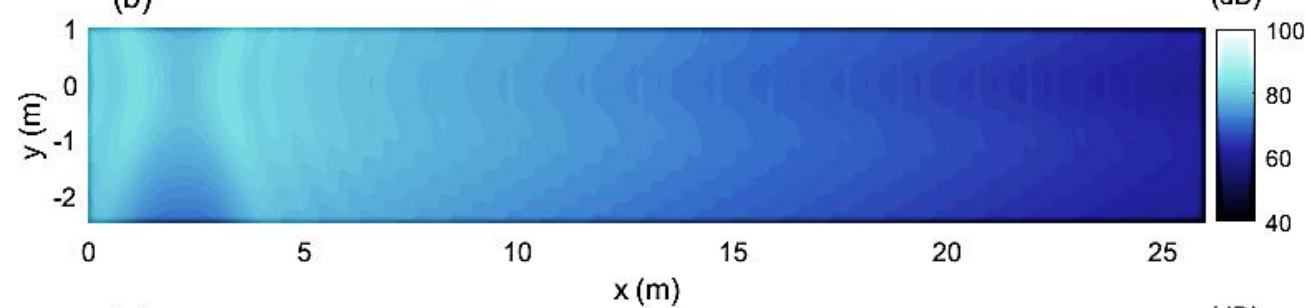

(c)

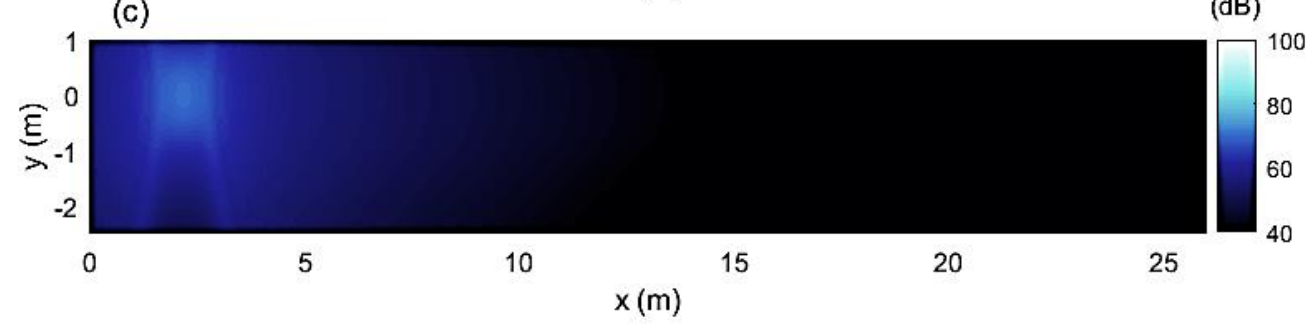

Figure 8. Direct sound pressure level on the train floor due to one wheel/rail contact, $\mathrm{dB}$ re $2.0 \times 10^{-5} \mathrm{~Pa}$. (a) $200 \mathrm{~Hz}$; (b) $800 \mathrm{~Hz}$; (c) $3150 \mathrm{~Hz}$.

At $200 \mathrm{~Hz}$ (Figure 8(a)), the sleeper radiation is dominant (see Figure 1), and the direct sound pressure at the train floor decays quickly with distance. At $800 \mathrm{~Hz}$, the rail is dominant in terms of sound power; the decay of sound pressure levels with distance along the train floor corresponds to the low decay rate of the rail vibration at this frequency (illustrated in Figure 3 ). At $3150 \mathrm{~Hz}$, the wheel contribution becomes significant and the sound pressure decays quickly away from the source (Figure 8(c)).

The sound pressure levels at the train floor along the train centreline at four example frequency bands are plotted in Figure 9. The direct sound shown here is the incident sound field, which represents the sound pressure at the floor position without allowing for the reflection from the floor. Only the noise from one wheel and the noise from the track excited by one wheel are considered here. The SEA model gives the average sound pressure for each subsystem, so the reverberant sound pressure levels are assumed constant within a given subsystem. 

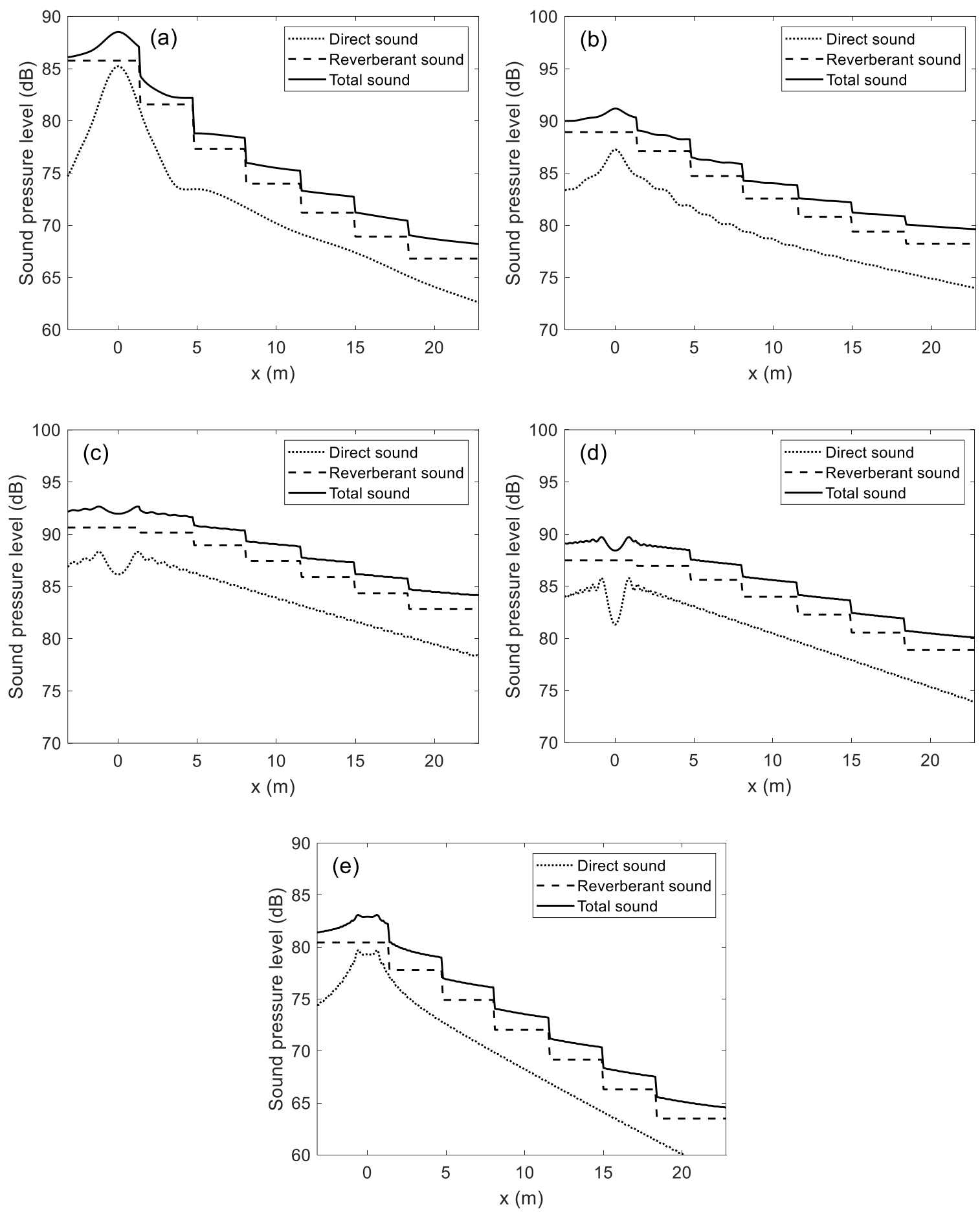

Figure 9. Incident sound pressure levels along the centreline of the train floor in example onethird octave bands, dB re $2.0 \times 10^{-5} \mathrm{~Pa}$. (a) $200 \mathrm{~Hz}$, (b) $400 \mathrm{~Hz}$, (c) $800 \mathrm{~Hz}$, (d) $1600 \mathrm{~Hz}$, (e) $3150 \mathrm{~Hz}$.

Figure 10 shows spectra of the contributions of the direct sound and reverberant sound to the total sound pressure levels at the train floor for selected subsystems. The direct sound is calculated at the centre of the floor for each subsystem and the reverberant sound is the average 
for that subsystem.
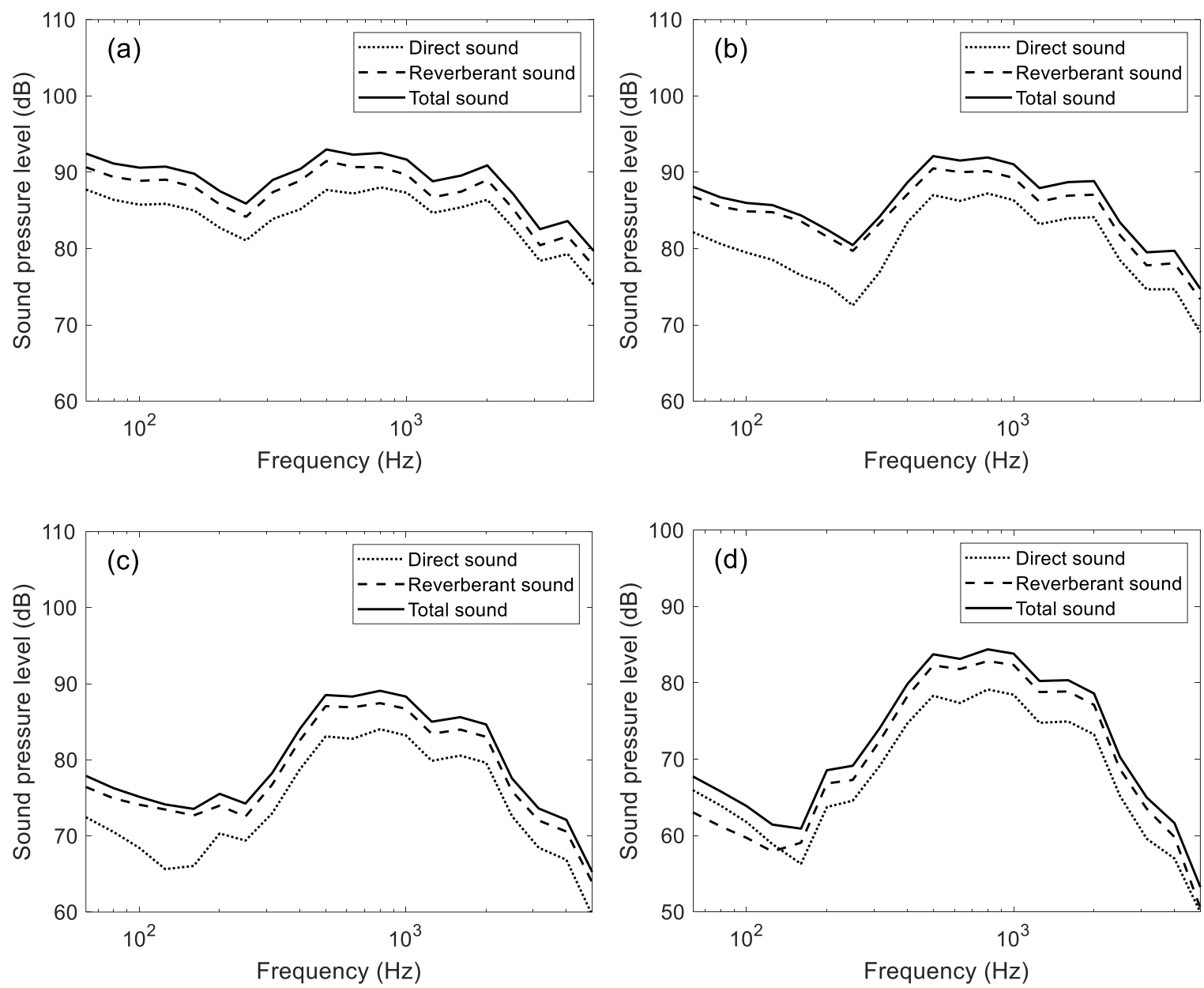

Figure 10. Comparison of the direct and reverberant sound in each subsystem, $\mathrm{dB}$ re $2.0 \times 10^{-5}$ Pa. (a) Subsystem 1, (b) subsystem 2, (c) subsystem 4, (d) subsystem 7 .

Figure 11 shows the relative contributions of the direct and the reverberant components of the overall sound power incident on the train floor. The direct sound power incident on the train floor is calculated from Equation (14). The reverberant sound power incident on the train floor is obtained by [17]

$$
W=\overline{\left\langle p_{\text {rev }}{ }^{2}\right\rangle} \frac{S}{4 \rho_{0} c_{0}}
$$

where $S$ is the area of the train floor. 


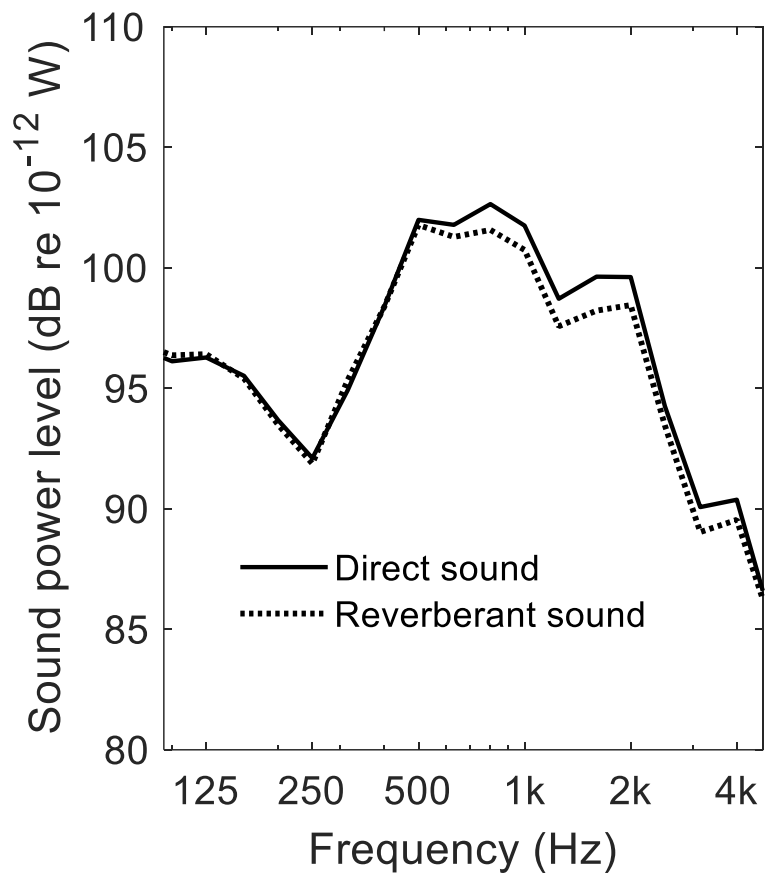

Figure 11. Relative contributions of direct and reverberant sound to the overall sound power incident on the train floor.

Although the reverberant sound pressure levels are higher than the direct sound pressure levels, as seen in Figure 9, the reverberant sound power is slightly lower than the direct sound power in Figure 11. This is a consequence of the fact that the relation between the sound pressure and the incident intensity is different for the direct field (approximately plane waves) and the reverberant field (Equation (18)).

\section{Comparison with laboratory measurements}

\subsection{Experimental set-up}

Experiments were conducted to measure the sound distribution on the floor of a 1:5 scale train model. For the measurements, a 1:5 scale ballasted track was installed in the anechoic chamber at the ISVR, University of Southampton, and mounted on wooden panels to represent an acoustically reflecting ground (see Figure 12). A 1:5 scale simplified car body, made of a dense foam which was sealed with varnish, was set up above the track using wooden supports; the track and the car body were not in contact. The track model is $2 \mathrm{~m}$ long and $0.8 \mathrm{~m}$ wide, and the train is $2.5 \mathrm{~m}$ long, $0.56 \mathrm{~m}$ wide and $0.45 \mathrm{~m}$ tall. The distance from the top of the sleepers to the train floor was about $0.23 \mathrm{~m}$. 
In the measurements, a sound source is used that consists of a driver connected to a stiff tube with a nozzle diameter of $1.5 \mathrm{~cm}$. The sound emitted from the tube is approximately omnidirectional. This arrangement allows the source to be placed at a precise location within the model. The source was excited with white noise, although the sound emitted from the nozzle is modified by the acoustic properties of the tube. The nozzle was located directly above the rail at $0.32 \mathrm{~m}$ from one end of the track. A microphone was used to measure the sound pressure along the centreline of the bottom surface of the train body with a spatial resolution of $0.1 \mathrm{~m}$.
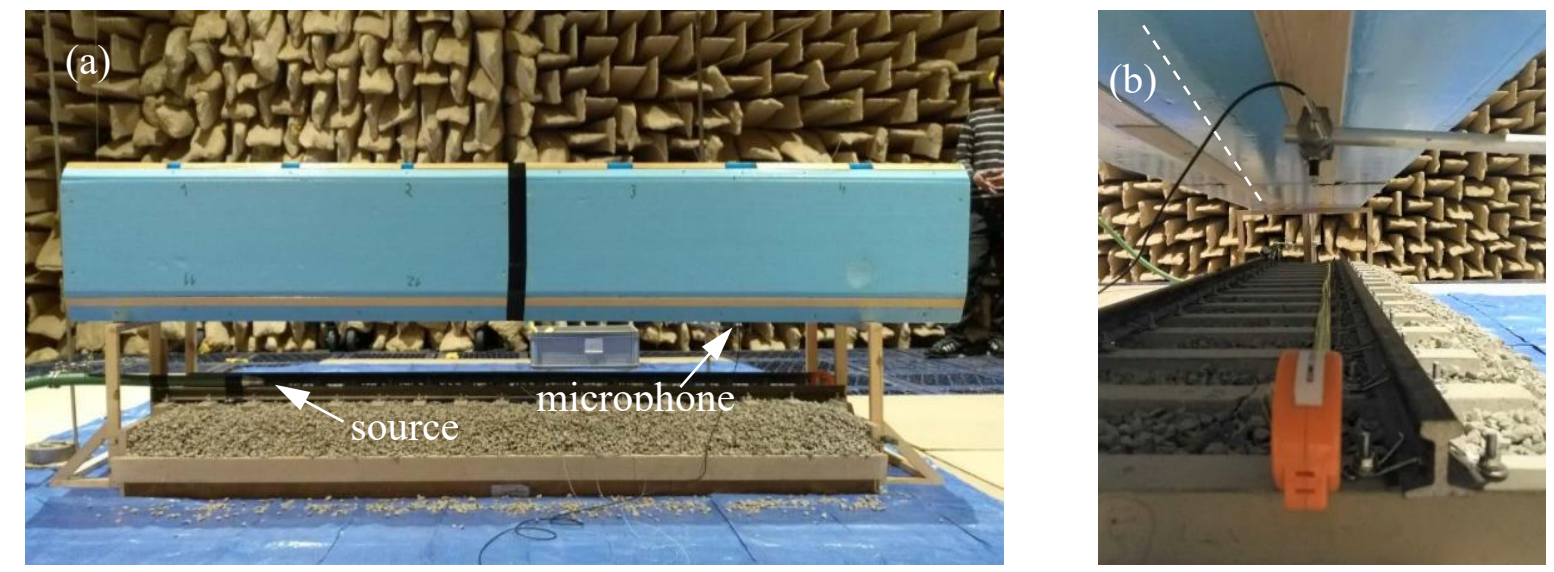

Figure 12. Experimental set up in anechoic chamber. (a) Front view, (b) side view (note that the microphone was located on the centreline of the train floor in the measurements, shown by the dashed line).

\subsection{Comparison of numerical and experimental results}

In the measurements, the sound pressure spectrum at the train floor was measured and was converted to $1 / 3$ octave bands. For comparison, the sound field was predicted using the model for a monopole source with a source strength determined from free-field measurements of the source. The absorption coefficient of the reduced scale ballast has been measured [24]. The absorption coefficient of the train floor has not been measured but it is set to 0.2 to be consistent with the field measurements in the next session. The area beneath the train is divided into five subsystems with equal lengths to calculate the reverberant sound. The criteria for using the SEA method on the scale model are satisfied for the $800 \mathrm{~Hz}$ band and above.

The direct and reverberant sound at the train floor have been calculated and their mean square pressures are added to obtain the total sound at the train floor. The results have been obtained in the frequency region between 1 and $5 \mathrm{kHz}$, corresponding to a range of 200-1000 $\mathrm{Hz}$ at full 
scale. The lower frequency limit is set to $1 \mathrm{kHz}$ as the signal-to-noise ratio in the measurements was not sufficient below this frequency. Results in example one-third octave bands are shown in Figure 13. The average differences in terms of the sound pressure levels over all 21 receiver positions at each frequency band between the predictions and the measurements are shown in Table 4.
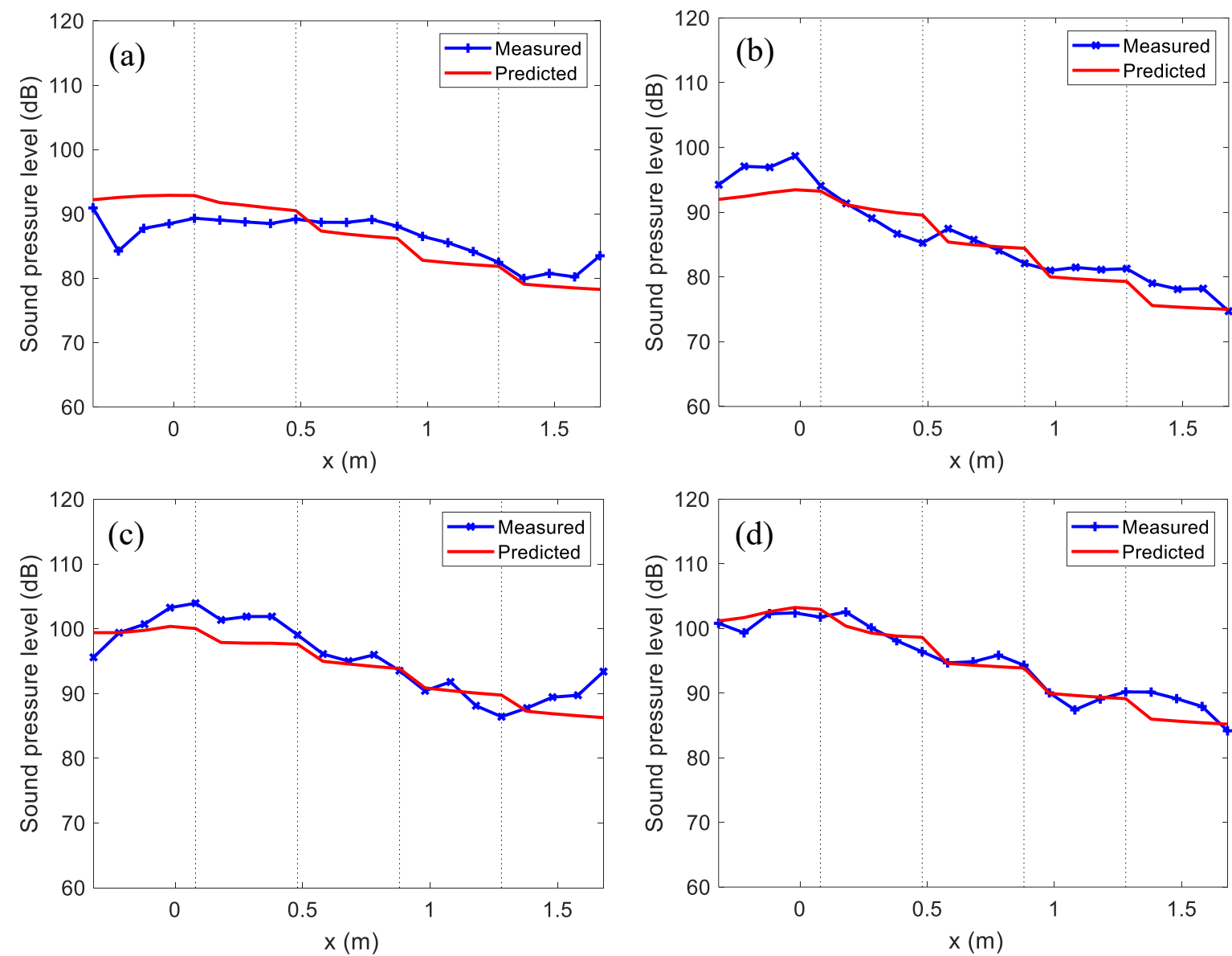

Figure 13. Comparison of sound pressure levels on the train floor obtained from the numerical simulation and experiment ( $x=0$ is the source location): (a) $1250 \mathrm{~Hz}$; (b) $2000 \mathrm{~Hz}$; (c) 3150

$$
\mathrm{Hz} \text {; (d) } 5000 \mathrm{~Hz} \text {. }
$$

Table 4. Average difference (over 21 receiver positions) in terms of the sound pressure level between the predictions and measurements $(\mathrm{dB})$.

\begin{tabular}{lcccccccc}
\hline \hline & $1 \mathrm{kHz}$ & $1.25 \mathrm{kHz}$ & $1.6 \mathrm{kHz}$ & $2 \mathrm{kHz}$ & $2.5 \mathrm{kHz}$ & $3.15 \mathrm{kHz}$ & $4 \mathrm{kHz}$ & $5 \mathrm{kHz}$ \\
\hline $\begin{array}{l}\text { Average } \\
\text { difference }\end{array}$ & -0.9 & 0.2 & -0.2 & -1.1 & 0.5 & -1.3 & -0.1 & -0.3 \\
\hline \hline
\end{tabular}


From these results it can be concluded that the SEA model combined with the equivalent source model is able to predict the sound beneath the train floor adequately for frequencies above 200 $\mathrm{Hz}$ at full scale.

\section{Comparison with field measurements}

Field measurements have been performed on a metro train. The vehicle tested had a length of $17.92 \mathrm{~m}$. In a first step an artificial source was introduced beneath the floor and the spatial decay of the sound was measured. In a second step measurements were made during train operation and the results were compared with predictions from the model.

\subsection{Measurement on a stationary train}

Field measurements have been performed to measure the sound decay below a stationary train due to a source located below the train floor. A dodecahedron omnidirectional source was located near the centreline of the train in the bogie region, resting on the ballast, see Figure 14(a). The diameter of the source is $0.45 \mathrm{~m}$. This was excited by broadband noise and the sound pressure results were expressed in one-third octave bands between 100 and $5000 \mathrm{~Hz}$. The microphones were placed $0.32 \mathrm{~m}$ above the sleepers at positions along the vehicle centreline with a spatial interval of $1.0 \mathrm{~m}$ (Figure 14(b)). The first microphone position was $2 \mathrm{~m}$ from the source.
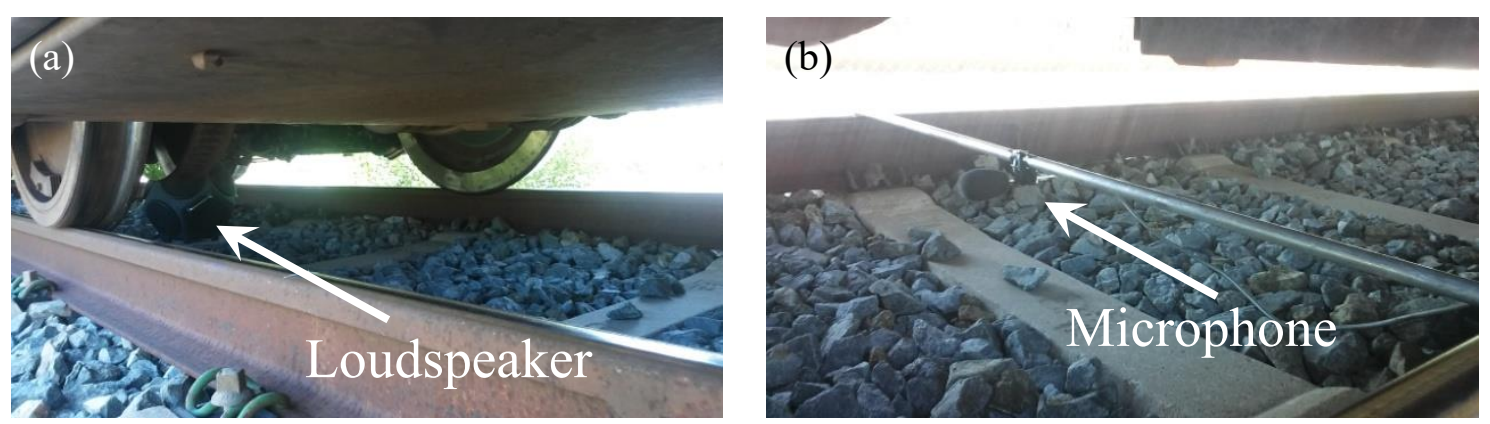

Figure 14. Field measurements on a stationary train. (a) Source location, (b) microphone locations.

Various pieces of equipment are mounted under the train floor, which will tend to weaken the direct sound and strengthen the reverberant one. The bottom of the equipment was $0.38 \mathrm{~m}$ above the sleepers while the train floor was $1.2 \mathrm{~m}$ above the sleepers. The equipment was simplified 
in the model as shown by the darker coloured areas in Figure 15. For this case, the area below the vehicle is divided into eight subsystems. Subsystems 1 and 8 are below the gangways at the two ends, subsystems 2 and 7 are for the two bogie areas and subsystems 3-6 are for the middle region.

Subsystems 1 and 8 have the smallest volumes and the number of modes in these subsystems exceeds 5 in the $315 \mathrm{~Hz}$ band. In most subsystems the mean absorption coefficients are small compared with 1 . The presence of the equipment beneath the train floor increases the dissipated power and reduces the transmitted power. The 'weak coupling' assumption is satisfied in the SEA model apart from subsystems 1 and 8 . However, this will not affect the accuracy significantly.

Train floor

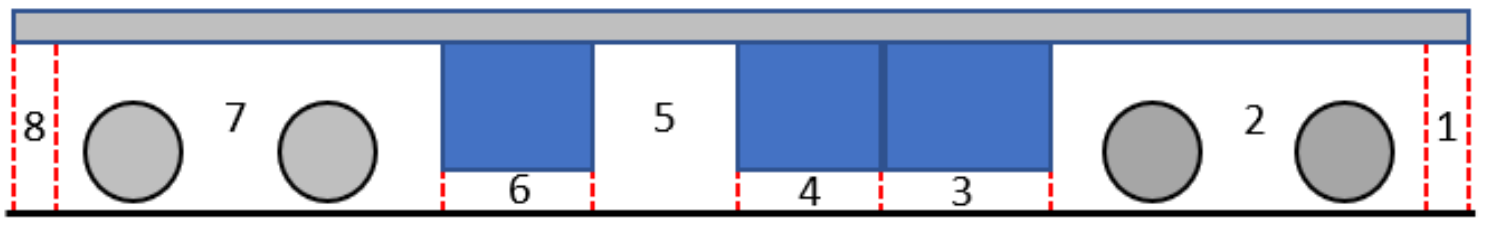

Ballast

Figure 15. Subdivision of the region below the vehicle (not to scale).

The source is located in subsystem 7. It is represented in the model by a monopole in a similar manner to the wheel noise described in Section 2.2. Account is also taken of the end surfaces of the equipment in subsystem 6 which can also reflect sound into the reverberant field in subsystem 7. An equivalent sound absorption coefficient 0.2 is used for the train floor and the equipment boxes. The predicted spatial decay beneath the train floor is compared with the measurements. As the source strength of the loudspeaker in the measurement is unknown, the predicted sound pressure levels have been shifted so that the predictions and measurements correspond to each other at the first position, $x=2 \mathrm{~m}$, to allow direct comparison. The results for example frequency bands are shown in Figure 16; other bands show similar results and the measured trends are captured well by the model. 

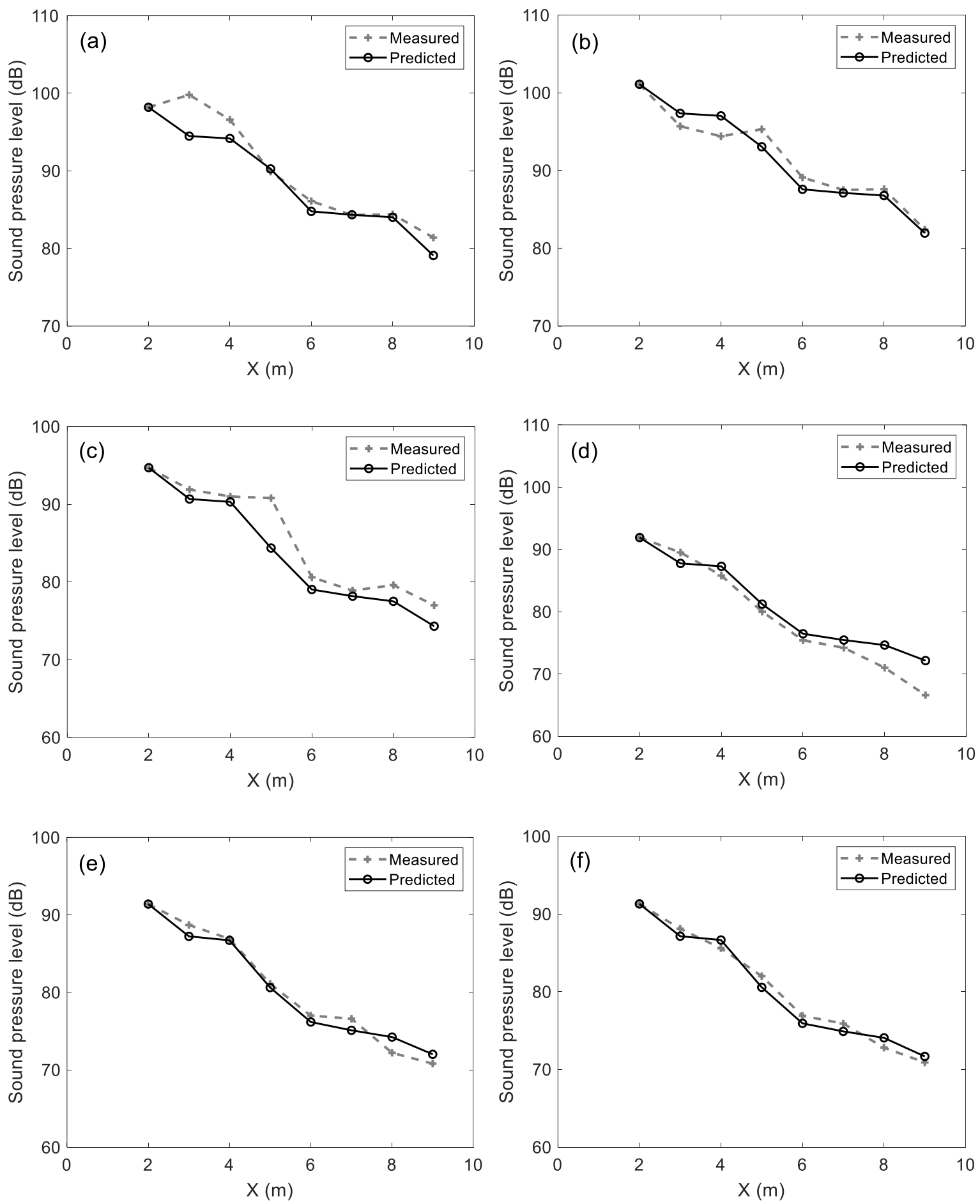

Figure 16. Comparison of sound pressure levels between predictions and field measurements on stationary train. (a) $160 \mathrm{~Hz}$; (b) $315 \mathrm{~Hz}$; (c) $630 \mathrm{~Hz}$; (d) $1250 \mathrm{~Hz}$; (e) $2500 \mathrm{~Hz}$; (f) $5000 \mathrm{~Hz}$.

\subsection{Measurement on a running train}

Field measurements were performed to measure the sound pressure below the same train during operation at $50 \mathrm{~km} / \mathrm{h}$. The sound pressure was recorded at various positions, including six 
microphones located below the train floor which are used here. These are labelled as 1002, 1007 and 1008 which were in the bogie area, microphone 1003 below the gangway and microphones 1012 and 1013 in the central part below the vehicle (see Figure 17).

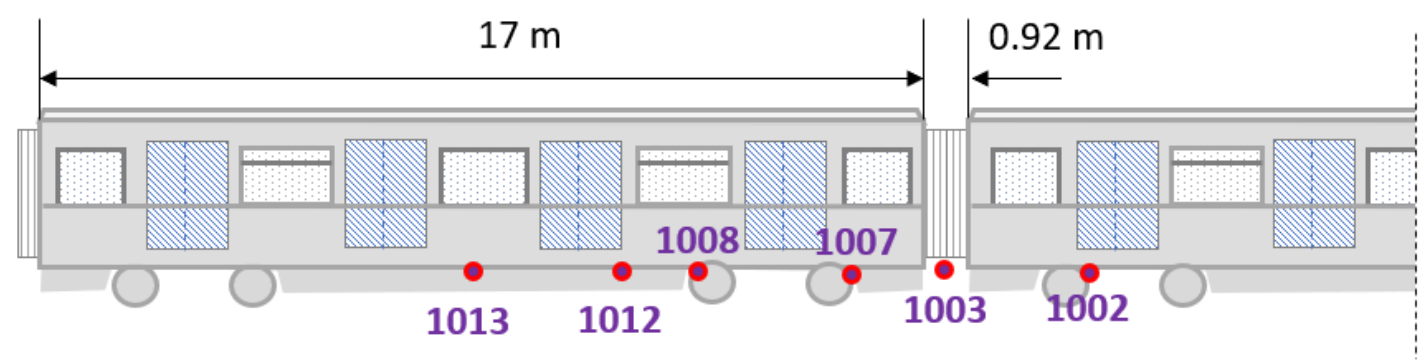

Figure 17. Measurement set up for microphone locations below the train.

Because of the presence of the underfloor equipment, direct sound is assumed only to exist on the train floor region belonging to subsystems 1, 2, 5, 7 and 8 (see Figure 15). The equipment blocks the direct sound from one end of the carriage from reaching the other end; therefore when calculating the direct sound on the train floor for these subsystems, only the sources below these subsystems are considered. The sound pressure impinging on the bottom of the equipment is assumed to be reflected into the corresponding subsystem and to contribute to the reverberant sound. The sound pressure below the vehicle is predicted following the procedure outlined in Sections 2 and 3. Although point 1002 was measured below the adjacent carriage, it is compared with an equivalent location in segment 7 as the configuration of the equipment below each coach is similar.

The sound power of the rolling noise obtained from the TWINS model is used as input to the predictions. The input parameters describing the test track are listed in Table 5. The wheels had a nominal diameter of $860 \mathrm{~mm}$ and were fitted with dampers.

Table 5. Parameters used to represent the railway track from the field measurements.

\begin{tabular}{llr}
\hline & Vertical & Lateral \\
\hline Rail bending stiffness $\left(\mathrm{Nm}^{2}\right)$ & $4.86 \times 10^{6}$ & $0.88 \times 10^{6}$ \\
Rail shear coefficient & 0.5 & 0.5 \\
Rail loss factor & 0.02 & 0.02
\end{tabular}


Cross receptance level (dB)

Pad stiffness $(\mathrm{N} / \mathrm{m})$

Pad loss factor

Sleeper mass (half, kg)

Distance between sleepers (m)

Ballast stiffness (N/m)

Ballast loss factor
$800 \times 10^{6}$

$100 \times 10^{6}$

0.2

150

1.0

$100 \times 10^{6}$

$35 \times 10^{6}$

1.0

In this particular track the sleeper spacing $(1 \mathrm{~m})$ is larger than usual and the rail pads are relatively stiff. It was therefore necessary to use a discretely supported beam model for the rail vibration [2]; moreover, the measured vibration of the rail and of the sleeper were used to adjust calculated results. The model was validated by comparing the results with field measurements of sound pressure at three receivers beside the track during train passages [25]. It was found that predictions and measurements have good agreement. The averaged difference in terms of the sound pressure levels obtained from the predictions and the measurements (averaging over the three receivers and over all the frequencies) is about $0.7 \mathrm{~dB}$. The maximum difference among the three receivers is about $5.6 \mathrm{~dB}$ at receiver 3 in the $200 \mathrm{~Hz}$ band. The differences in terms of overall sound pressure levels at the receivers are about $0.44,0.44$ and $1.12 \mathrm{~dB}(\mathrm{~A})$ respectively. The sound powers obtained from TWINS for this configuration are given in Figure 18.

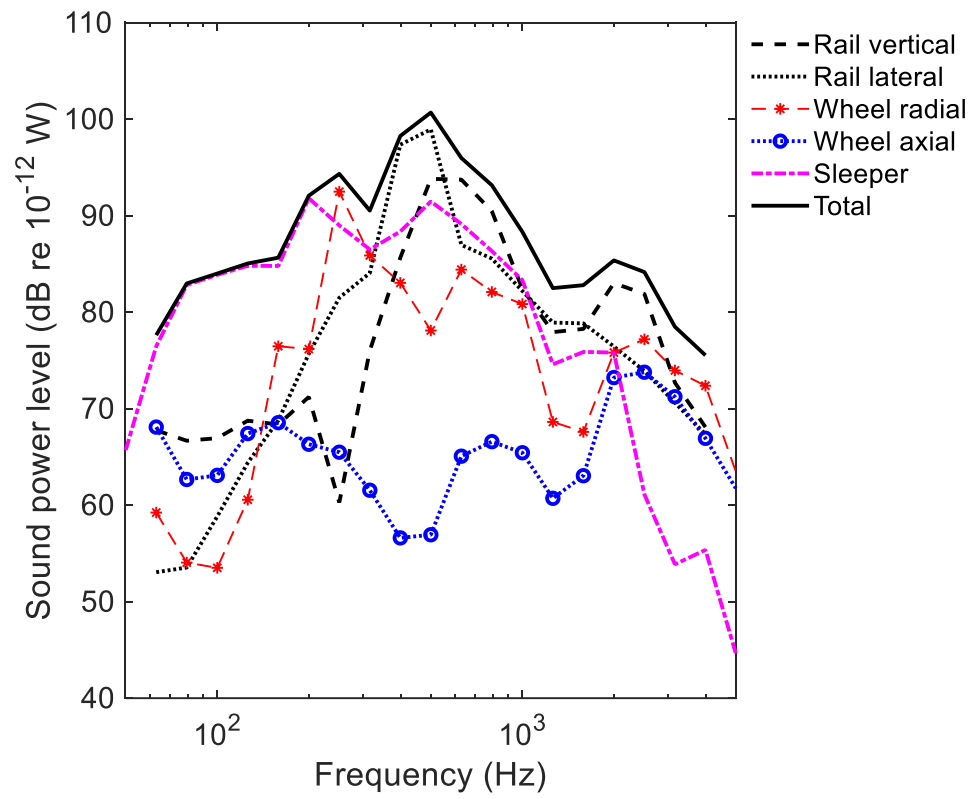

Figure 18. Rolling noise sound power representing the field test. 
The predictions of the sound pressure levels at the measurement positions below the floor are compared with field measurements in Figure 19. Points 1002, 1007 and 1008 are located in the same subsystem in the bogie region, so the predictions at the three points are similar, and they are compared together in Figure 19(a).
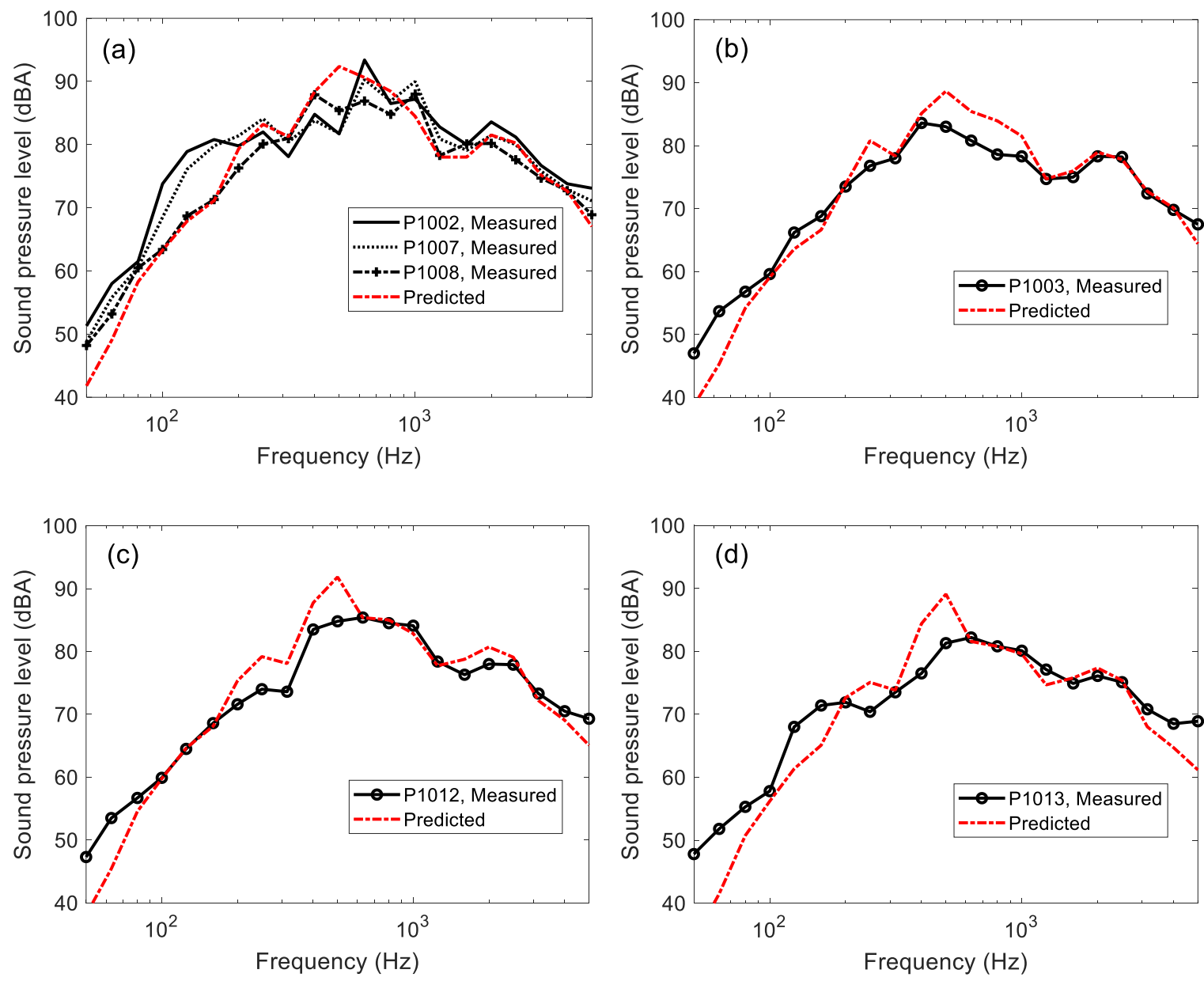

Figure 19. Comparison of sound pressure levels between predictions and field measurements.

(a) Comparisons at the bogie area; (b) comparison at point 1003; (c) comparison at point 1012;

(d) comparison at point 1013 .

The overall sound pressure levels and the average differences between the predictions and the measurements are shown in Table 6. The predictions of sound pressure levels at the three positions in the bogie area (1002, 1007 and 1008) agree well with the measurements; the relative error of their overall sound pressure levels is less than $2 \mathrm{~dB}$. For the two positions, 1012 and 1013 in the middle region of the vehicle, the predictions agree well with the measurements apart from the region between $250 \mathrm{~Hz}$ and $500 \mathrm{~Hz}$, where the predictions are higher. At point 1003, the one below the gangway, very good agreement is found but again in the middle frequency 
region, in this case between 500 and $1000 \mathrm{~Hz}$, some differences appear. The differences in overall level at these three locations outside the bogie area are between 2 and $3 \mathrm{~dB}(\mathrm{~A})$, see Table 6.

Table 6. Overall sound pressure levels on train floor $(\mathrm{dB}(\mathrm{A}))$.

\begin{tabular}{lcccccc}
\hline \hline & Point & Point & Point & Point & Point & Point \\
& 1002 & 1003 & 1007 & 1008 & 1012 & 1013 \\
& (bogie) & (gangway) & (bogie) & (bogie) & (centre) & (centre) \\
\hline Prediction & 96.7 & 93.2 & 97.2 & 96.8 & 94.8 & 91.6 \\
Measurement & 96.9 & 90.3 & 96.1 & 94.9 & 92.5 & 89.1 \\
Difference & -0.2 & 2.9 & 1.1 & 1.9 & 2.3 & 2.5 \\
\hline \hline
\end{tabular}

\section{Conclusions}

A methodology has been presented to predict the sound pressure beneath a train floor due to rolling noise during train operation. It can also be used for other sources such as traction and auxiliary equipment if the corresponding sound powers are known. The sound is separated into the direct and reverberant components, with a set of equivalent sources being used to predict the direct sound and SEA being considered for the reverberant field. The source strengths of the wheel, the rail and the sleepers have been determined by using sound powers obtained from the TWINS model. The sound pressure on the train floor is highest in the bogie region and decays with increasing distance from the source, the decay rate being dependent on frequency.

Comparisons have been made with both laboratory and field measurements of sound pressure below a vehicle. In the laboratory measurements, performed on a 1:5 scale model, the sound pressure distribution along the train floor centreline was found to agree well with the predicted results above $200 \mathrm{~Hz}$ (full scale frequency). Field measurements on a static train using an omindirectional source also show good agreement with the sound pressure decay under the vehicle. For a train in running operation, the sound pressure spectrum measured at six locations below the vehicle was in reasonable agreement with the predictions, with overall sound pressure levels differing by less than $3 \mathrm{~dB}$.

This approach can benefit the prediction of train interior noise as the incident sound on the train floor is an essential component for interior noise calculations. 


\section{Acknowledgements}

This work has been funded by the China Scholarship Council and the RUN2Rail H2020/Shift2Rail project (Grant agreement No: 777564). The contents of this publication only reflect the authors' views and the Shift2Rail Joint Undertaking is not responsible for any use that may be made of the information contained in the paper. The authors would also like to thank Dr. Hongseok Jeong for his assistance in the laboratory measurements and Metro de Madrid for assistance in the field tests.

\section{References}

[1] P. Bouvet, M. Rissmann, Industrial methodologies for the prediction of interior noise inside railway vehicles: airborne and structure bone transmission, 13th International Workshop on Railway noise, Ghent, Belgium. 2019.

[2] D. Thompson, Railway noise and vibration: mechanisms, modelling and means of control, Elsevier, 2008.

[3] C. J. C. Jones, D. J. Thompson, and T. P. Waters, Application of numerical models to a system of train-and track-mounted acoustic shields, International Journal of Acoustics and Vibration, 6 (4) (2001) 185-192.

[4] D. J. Thompson, B. Hemsworth, and N. Vincent, Experimental validation of the TWINS prediction program for rolling noise, part 1: description of the model and method, Journal of Sound and Vibration, 193 (1) (1996) 123-135.

[5] X. Zhang, D. Thompson, E. Quaranta and G. Squicciarini, An engineering model for the prediction of the sound radiation from a railway track, Journal of Sound and Vibration, 461 (2019) 114921.

[6] C. M. Nilsson, C. J. C. Jones, D. J. Thompson and J. Ryue, A waveguide finite element and boundary element approach to calculating the sound radiated by railway and tram rails. Journal of Sound and Vibration, 321 (3) (2009) 813-836.

[7] J. Ryue, S. Jang and D. J. Thompson, A wavenumber domain numerical analysis of rail noise including the surface impedance of the ground, Journal of Sound and Vibration, 432 (13) (2018) 173-191.

[8] T. Kitagawa and D. J. Thompson, The horizontal directivity of noise radiated by a rail and implications for the use of microphone arrays, Journal of Sound and Vibration, 329 (2) (2010) 202-220.

[9] D. J. Thompson, C. J. C. Jones and N. Turner, Investigation into the validity of twodimensional models for sound radiation from waves in rails, Journal of the Acoustical Society of America, 113 (2003) 1965-1974.

[10] W. Dai, X. Zheng, L. Luo, Z. Hao and Y. Qiu, Prediction of high-speed train fullspectrum interior noise using statistical vibration and acoustic energy flow, Applied Acoustics, 145 (2019) 205-219.

[11] X. Zheng, Z. Hao, X. Wang and J. Mao, A full-spectrum analysis of high-speed train interior noise under multi-physical-field coupling excitations, Mechanical Systems and Signal Processing, 75 (2016) 525-543. 
[12] X. Zheng, W. Dai, Y. Qiu, Z. Hao, Prediction and energy contribution analysis of interior noise in a high-speed train based on modified energy finite element analysis, Mechanical Systems and Signal Processing, 126 (2019) 439-457.

[13] J. Forssén, S. Tober, A. C. Corakci, A. Frid and W. Kropp, Modelling the interior sound field of a railway vehicle using statistical energy analysis, Applied Acoustics, 73 (4) (2012) 307-311.

[14] F. J., Fahy, A note on the subdivision of a volume of air in a vehicle enclosure into sea subsystems, Journal of Sound Vibration, 271 (2004) 1170-1174.

[15] H. Jang and C. Hopkins, Prediction of sound transmission in long spaces using ray tracing and experimental Statistical Energy Analysis, Applied Acoustics, 130 (2018) 15-33.

[16] M. Sadri, J. Brunskog and D. Younesian, Application of a Bayesian algorithm for the Statistical Energy model updating of a railway coach, Applied Acoustics, 112 (2016) 84107.

[17] F. Fahy and D. Thompson, eds. Fundamentals of sound and vibration, CRC Press, Boca Raton, 2016.

[18] R. J. M. Craik, Sound Transmission through Buildings using Statistical Energy Analysis, England Gower Publishing Limited, Aldershot, 1996.

[19] R. A. Broadbent, D. J. Thompson and C. J. C. Jones. The acoustic properties of railway ballast. 8th European Conference on Noise Control, Edinburgh, UK. 2009.

[20] A.D. Pierce, R.T. Beyer, Acoustics: An introduction to its physical principles and applications. Acoustical Society of America, 1990.

[21] A. Le Bot, Foundation of statistical energy analysis in vibroacoustics, OUP, 2015.

[22] B.R. Mace, Statistical energy analysis: coupling loss factors, indirect coupling and system modes. Journal of Sound and Vibration 279.1-2 (2005) 141-170.

[23] T. Lafont, N. Totaro, A. Le Bot, Coupling strength assumption in statistical energy analysis, Proc. R. Soc. A 473, 2017.

[24] X. Zhang, D. Thompson, H. Jeong and G. Squicciarini, The effects of ballast on the sound radiation from railway track, Journal of Sound and Vibration, 399 (2017) 137-150.

[25] P. Bouvet, M. Rissmann, D. Thompson, X. Liu, H. Li, G. Squicciarini, G. Xie, Validation of complete virtual test method for structure-borne and airborne noise transmission. RUN2Rail Deliverable 4.3, August 2019 (www.run2rail.eu). 